\title{
Agrotóxicos: \\ eficiência econômica e injustiça socioambiental
}

\author{
Pesticides: \\ economic efficiency and social and environmental injustice
}

M arcelo M otta Veiga ${ }^{1}$

¿Escola Nacional de Saúde Pública, Fiocruz. Rua Leopoldo Bulhões 1480/50 andar, $M$ anguinhos. 21041-210 Rio de Janeiro RJ. mveiga@ensp.fiocruz.br
Abstract This study analyzed the inverse relationship between economic efficiency and social and environmental justicein the use of pesticides. The use of pesticides tends to improve economic efficiency by increasing agricultural productivity, however, it can also increase social and environmental injustice. This inverse relationship was inferred since the economic efficiency gained with the use of pesticides is [usually] associated with some kind of social and environmental injustice. This study also analyzed the impact of regulatory measures to control the use and handling of pesticides. Strict pesticide regulations could jeopardize agricultural competitiveness, especially in some small rural communities; therefore, the cost-benefit results of pesticides regulations could be negativeand detrimental comparing to potential pesticide effects on human health and the environment. This study also concluded that some regulatory control is needed; however, it should bewell designed and managed.

Key words Environmental injustice, Economic efficiency, Pesticide
Resumo Este estudo analisou a relação inversa entre eficiência econômica ejustiça socioambiental na utilização de agrotóxicos. A utilização de agrotóxicos tenderia a maximizar a eficiência econômica através de ganhos de produtividade; no entanto, poderia agravar a injustiça socioambiental. Inferiu-seessa relação inversa, uma vez que a eficiência econômica pela utilização de agrotóxicos estaria associada a alguma injustiça socioambiental. Este estudo analisou, ainda, o impacto deinstrumentos regulatórios no controle da utilização e do manejo de agrotóxicos. U ma legislação que reduza compul soriamente a utilização de agrotóxicos poderia agravar diversos problemas socioeconômicos, especialmente em pequenas comunidades rurais. Concluiu-se queeventuais restrições na utilização de agrotóxicos em sistemas produtivosquedependam dessasmatérias-primas para sustentar sua economia poderia ser bastante prejudicial. Q uanto à necessidade de intervenção estatal para regular a utilização de agrotóxicos, esteestudo concluiu quea questão não deveria ser sobre a necessidade ou não de legislação, mas sim como deve ser a forma dessa intervenção.

Palavras-chave Injustiça socioambiental, Eficiência econômica, Agrotóxico 
Introdução

A relação entre agricultura e saúde pública sempre foi muito grande, seja na função de supridora de alimentos, seja pelos riscos à saúde humana e ao meio ambiente causados pela utilização de agrotóxicos. 0 crescimento da demanda por alimentos queacompanhou a explosão demográfica resultou, em um primeiro momento, na intensificação da cultura em terras mais férteis e, em um segundo momento, na expansão dessas frontei ras agrícolas para áreas menos produtivas. A importância da agricultura na economia brasileira pode ser demonstrada por sua participação no Produto Interno Bruto (PIB) brasileiro, como pode ser verificado na Tabela 1.

Desse uso intensivo e impróprio do solo, aliado a uma adoção de métodos e técnicas inadequadas de manejo e conservação da terra, decorreu uma forte degradação nos ecossistemas, que favoreceu processos erosivos que empobreceram o solo reduzindo sua produtividade. Essas práticas inadequadas são, ainda, mais comuns em pequenas comunidades rurais e em culturas intensivas em agrotóxicos. 0 resultado desse conjunto de aspectos negativos foi um aumento da incidência e da severidade das pragas e doenças.

0 modelo de produção agrícola brasileiro, historicamente, baseia-se na utilização de agrotóxicos para compensar problemas do processo produtivo. Neste contexto, os agrotóxicos foram

Tabela 1

Participação da agricultura no PIB.

Participação da agricultura no PIB do Brasil

( $R$ \$ milhões de 2004)

\begin{tabular}{cccc}
\hline Ano & PIB & Agricultura & $\%$ \\
\hline 2004 & 1.775 .700 & 379.897 & $21,39 \%$ \\
2003 & 1.702 .492 & 369.204 & $21,69 \%$ \\
2002 & 1.693 .265 & 342.970 & $20,25 \%$ \\
2001 & 1.661 .256 & 309.959 & $18,66 \%$ \\
2000 & 1.639 .733 & 304.160 & $18,55 \%$ \\
1999 & 1.571 .217 & 310.476 & $19,76 \%$ \\
1998 & 1.558 .972 & 310.100 & $19,89 \%$ \\
1997 & 1.556 .918 & 312.836 & $20,09 \%$ \\
1996 & 1.507 .599 & 312.253 & $20,71 \%$ \\
1995 & 1.468 .556 & 315.043 & $21,45 \%$ \\
1994 & 1.409 .041 & 309.487 & $21,96 \%$ \\
\hline
\end{tabular}

Fontes: PIB total IBGE; PIB agro: CEPEA. introduzidos na agricultura brasi leira como uma tentativa de corrigir as necessidades do solo e prevenir/eliminar as pragas que prejudicariam a produtividade. Buscava-se, ao aumentar a produtividade, elevar a eficiência econômica do processo produtivo rural.

Talvez, essa tenha sido a razão porque a venda de agrotóxicos no Brasil venha crescendo tanto nos últimos anos, tornando o país um dos maiores consumidores de agrotóxicos do mundo. Com isso, só no setor agrícola, cerca de 12 milhões de trabalhadores rurais seriam expostos diariamente aos agrotóxicos ${ }^{1}$.

Contudo, o papel do agrotóxico neste sistema produtivo pode ser analisado, tanto do ponto de vista do seu risco potencial à saúde humana e ao meio ambiente (negativo), quanto do ponto de vista do seu papel de agente necessário e catal isador do processo produtivo rural (positivo).

Neste estudo, objetivou-se analisar a relação inversa entre eficiência econômica e justiça socioambiental. Essa relação inversa funciona para ambos os lados, e pode ser caracterizada como: 0 quanto de decréscimo em eficiência econômica se estaria disposto a aceitar para que se aumentea justiça socioambiental, ou seja, o quanto um tomador de decisões estaria disposto a sacrificar (perder) de um critério (eficiência econômica) para se obter ganhos em outro critério (justiça socioambiental), ou vice-versa.

A decisão sobre a viabilidade da utilização de agrotóxicos no sistema produtivo rural poderia ser caracterizada como se balanceando essa duplicidade de efeitos concorrentes, um positivo (aumentar eficiência econômica) e outro negativo (diminuir a justiça socioambiental), ou viceversa (diminuindo a eficiência econômica e aumentando a justiça socioambiental). A existência dessa relação inversa implica na necessidade de uma quantidade de injustiça socioambiental adicional para se elevar a eficiência econômica em al guns processos produtivos rurais em certas localidades.

\section{A utilização de agrotóxicos}

O uso de agrotóxicos é um dos recursos mais utilizados pelos produtores rurais para tentar compensar a perda de produtividade provocada pela degradação do solo e controlar o aparecimento de doenças. Porém, muitas vezes, essa utilização de agrotóxicos é feita de forma inadequada, sem o conhecimento das reais necessidades do solo e das plantas. 
A diagnose de doenças de plantas no campo é tarefa difícil e um diagnóstico incorreto tem induzido à utilização de agrotóxicos de maneira e em quantidades inadequadas, gerando resultados duvidosos e elevando o risco à saúde humana e ao meio ambiente. Três fatores estão sempre presentes sinergicamenteem qualquer doença de planta: um agente causal, um hospedeiro suscetível e condições climáticas favorávei s,3.3.

No entanto, controlar uma doença não ésimplesmente tentar eliminá-la tão logo apareça. 0 manejo e o controle de uma doença devem procurar evitar que ela apareça ou evitar que, no caso de detecção da sua presença, resulte em perdas "significativas" de qualidade e quantidade dos produtos. Os agrotóxicos mais eficientes seriam capazes de eliminar cerca de $95 \%$ da população da praga. Por isso, considera-se um bom manejo e uso de agrotóxicos quando, ao final de um ciclo de produção, um número menor do que $10 \%$ dos frutos foram danificados ${ }^{4,5}$.

Os agrotóxicos são compostos que possuem uma grande variedade de substâncias químicas ou produtos biológicos e que foram desenvolvidos de forma a potencializar uma ação biocida, ou seja, são desenvolvidos para matar, exterminar e combater as pragas agrícolas. Deste modo, representam um risco em potencial para todos os organismos vivos. Eles podem ser absorvidos via dérmica, inspirados pelos pulmões ou ingeridos em produtos contaminados. Os efeitos adversos dos agrotóxicos à saúde dependem de suas características químicas, da quantidade absorvida ou ingerida, do tempo de exposição e das condições gerais de saúde da pessoa contaminada ${ }^{6,7}$.

Por atuarem sobre processos vitais, têm grande parte dos seus efeitos negativos agindo diretamente sobre a saúde humana. 0 mai or penalizado nessa busca pela eficiência econômica seria o trabalhador rural, uma vez que estaria diretamente e quase que diariamente exposto aos riscos associados a este processo.

Estes efeitos sobre a saúde humana poderiam ser divididos em agudos e crônicos. Os efeitos agudos apareceriam logo após o contato da pessoa com o agrotóxico e apresentariam características marcantes (espasmos musculares, convulsões, náuseas, desmaios, vômitos, diarréias e dificuldades respiratórias). Os efeitos crônicos seriam percebidos semanas, meses ou anos após o contato com esses produtos, sendo muitas vezes difíceis de serem relacionados ao verdadeiro agente causador (agrotóxico). Porém, esta divisão seria meramente acadêmica, uma vez que es- ses dois tipos de efeitos coexistem e interagem sinergicamente potencializando ainda mais os resultados finais ${ }^{8,9}$.

Ressalta-se que os efeitos negativos de uma possível contaminação por agrotóxicos à saúde humana seriam agravados em pequenas comunidades rurais, pelas precárias condições sanitárias, deficiência no sistema de saúde local e falta de infra-estrutura da maioria da população local, normalmente, de baixas condições socioeconômicas.

Outro aspecto relevante no caso de contaminação por agrotóxicos em populações de pequenas comunidades rurais seria o fato de que a maioria dos trabalhadores tem nível de instrução inadequado para o desempenho da função. Esta inadequação se dá porque a capacidade de leitura do rótulo e entendimento dos procedimentos adequados de preparação e aplicação é uma condição indispensável para o manejo e aplicação dos agrotóxicos de forma correta ${ }^{10,11}$.

Alguns estudosjá demonstraram que, além do efeito esperado pelos produtores rurais deaumento na produtividade rural, existe uma relação positiva entre o uso de agrotóxicos, a degradação ambiental e os danos à saúde humana ${ }^{12}$.

\section{Injustiça socioambiental}

O conceito de injustiça ambiental seria oriundo de um movimento iniciado no final da década de 70, nos Estados Unidos, que afirmava que certos grupos estariam mais expostos a riscos socioambientais. Os grupos que suportariam a maior parte dos efeitos negativos à saúde e ao meio ambiente seriam os de classes socioeconômicas mais baixas, o que associaria a injustiça ambiental a uma condição social. Assim sendo, neste estudo, utilizou-se a terminologia injustiça socioambiental ao invés de injustiça ambiental.

Essa condição de injustiça socioambiental estaria diretamente relacionada ao sistema de poder político-econômico, onde os grupos mais poderosos transfeririam certos riscos socioambientais aos grupos mais frágeis. Esta condição reforçaria a relação entre risco socioambiental e desigual dade socioeconômica ${ }^{13,14}$.

A idéia de injustiça socioambiental tomaria como referência uma situação hipotética onde todos os grupos sociais deveriam ter acesso igualitário aos recursos naturais: terra, ar e água. Com isso, a injustiça socioambiental poderia ser caracterizada de uma forma mais direta por uma desigualdade no acesso aos recursos naturais 
como ar, água e solo de melhor qualidade, ou indiretamente, por uma desigualdade no acesso às tecnologias e aos riscos associados a esses re cursos. Assim, os grupos de maior poder político esocioeconômico tenderiam ater maior acesso aos recursos e maior rejeição aos riscos socioambientais, representando as forças desiguais interagindo nesse cenário.

Portanto, poderia existir a necessidade de uma intervenção estatal (legislação) para reequilibrar esse sistema de acesso a recursos e riscos, de modo que a sociedade como um todo passasse a operar em um nível socioambiental (justiça) mais eficiente ${ }^{15}$.

Contudo, acirramentos legais que visem primariamente limitar o risco socioambiental através de restrições à utilização de agrotóxicos em certas comunidades rurais poderiam, nos seus efeitos secundários, gerar impactos mais graves (e.g. aumentar a pobreza, gerar desemprego e recessão econômica local) do que os possíveis prejuízos à saúde humana e ao meio ambiente ocasionados pelo uso desses mesmos agrotóxicos ${ }^{16,17}$.

Aspectos econômicos da utilização de agrotóxicos

A utilização de agrotóxicos na agricultura tem um forte impacto socioeconômico, pois gera custos e benefícios à sociedade, afetando de forma diferente todos os atores sociais envolvidos (indústria química, trabal hadores e produtores rurais e consumidores).

0 agrotóxico pode ser visto como um insumo necessário à viabilidade da maioria dos sistemas produtivos rurais, uma vez que muitos desses sistemas produtivos rurais só se sustentariam devido à utilização de agrotóxicos para compensar sua perda de produtividade. Em muitos casos, a utilização de agrotóxicos poderia ser considerada como uma questão de sobrevivência. Para a maioria dos produtores e trabalhadores rurais, uma cultura agrícola sem a presença de agrotóxicos não seria uma alternativa viável.

0 benefício mais comum associado à utilização de agrotóxicos seria o aumento na produtividade da lavoura, ou seja, uma maior produção agrícola colhida para uma determinada área plantada. Este aumento na produtividade reduziria a demanda por recursos naturais (e.g. terra eágua) e por recursos tecnológicos (e.g. mecanização) para a produção de uma mesma quantidade de produtos agrícolas a ser ofertada. Estes fatores poderiam acabar beneficiando os consumidores finais através de um aumento na oferta e uma redução dos custos unitários de produção, o que viabilizaria uma redução nos preços desses produtos a serem ofertados.

A possibilidade de redução de custos e preços, além de tornar os produtores locais comparativamentemaiscompetitivos, possibilitaria que uma parte da população, normalmente de nível de renda mais baixa, pudesse ter acesso a produtos que anteriormente não teria.

0 acesso incremental dessa camada mais carente da população a certos alimentos poderia resultar em uma el evação nas condições de saúde dessa parte da população, pelo aumento na quantidadee/ou na qualidade da cesta dealimentos consumidos. Portanto, dentro dessa lógica meramente econômica, a utilização de agrotóxicos poderia levar a uma relação custo e ben efício positiva para a saúde humana em relação ao uso de agrotóxicos.

Diversos estudos ${ }^{18,19,20}$ já mostraram que tentativas compul sórias de redução na utilização de agrotóxicos poderiam resultar numa perda para a sociedade em proporções maiores do que os benefícios para o meio ambiente e para a saúde humana correspondentes. Porém, esses estudos assumiriam que a utilização de agrotóxicos seria feita de maneira adequada, prudente e racional.

Deste modo, uma redução compulsória da utilização de agrotóxicos poderia provocar externalidades que normalmente passariam despercebidas pela maioria da população (e.g. desemprego, aumento dos custos de produção, perdas de escala, redução de oferta de produtos e queda da competitividade da economia rural local).

Contudo, existiria uma desconexão entre os atores sociais que se beneficiam e os que se prejudicam com o uso de agrotóxicos. Os maiores penalizados, a princípio, seriam os trabalhadores rurais que estariam, direta e quase que diariamente expostos, e que na maioria das vezes representam a parte mais frágil de toda cadeia produtiva. Dentre os maiores beneficiários, estariam a indústria química, os produtores rurais e os consumidores finais ${ }^{21,22,23,24}$.

Por isso, dever-se-ia tentar equilibrar os benefícios econômicos da utilização de agrotóxicos com a proteção ao meio ambiente e à saúde humana, a fim de evitar que nessa busca pela eficiência econômica não se agrave os problemas de injustiça socioambiental, especialmente em pequenas comunidades rurais. Deve-se, ainda, limitar as intervenções estatais aos casos onde forem realmente necessárias ${ }^{25}$. 
A percepção e a disposição a aceitar (DAA) riscos

A disposição a aceitar (DAA) um risco adicional por uma pessoa ou uma comunidade rural estaria baseada no nível de risco percebido e não no risco real de danos ambientais e à saúde humana que estariam submetidos. Por isso, a disponibilidade e a qualidade da informação sobre potenciais riscos na utilização de agrotóxicos poderiam alterar essa percepção de risco e, conseqüentemente, a disposição a aceitar certo dano ambiental ou prejuízo à saúde humana.

Então, poder-seia dizer que o produtor rural, a população local e os demais atores sociais envolvidos dependeriam da informação sobre os riscos potenciais da utilização de agrotóxicos para tomar suas decisões de prevenção de forma mais eficiente ${ }^{26,27}$.

MCDaniels et al..$^{27}$ estudaram de que modo essa percepção de risco poderia influenciar no comportamento e na vontade de reduzir o nível derisco das pessoas. Eles acharam evidência que, para riscos mais bem definidos, a exposição pessoal seria um fator determinante, e para riscos menos definidos, o medo e a severidade seriam mais importantes. Assim, assumindo-se que 0 risco associado à utilização de agrotóxicos seria um fator de exposição pessoal dos trabalhadores rurais, a divulgação da informação sobre o risco poderia ser encarada como medida preventiva para redução de seus impactos negativos.

Conseqüentemente, os diferentes atores sociais não perceberiam os riscos ambientais e à saúde humana do mesmo modo (pois não teriam o mesmo acesso às informações) e, assim sendo, reagiriam de forma diferente quando expostos à mesma situação de fato. Diferentes trabaIhadores rurais, também, não perceberiam os riscos associados à utilização de agrotóxicos da mesma forma ${ }^{29}$. Conseqüentemente, essas diferenças na percepção do risco deveriam ser mais bem compreendidas visando ap rimorar possíveis interven ções estatais no controle sobre o uso de agrotóxicos.

Um modelo simplificado para representar a função disposição a aceitar (DAA) poderia ser feita da seguinte forma:

$\operatorname{DAA}\left(q_{0}, q_{1}\right)=f\left(q_{0}, q_{1}, x, y, z \ldots\right)=f\left(q_{0}, q_{0}+\right.$ $\Delta q, x, y, z \ldots)$

$\rightarrow$ Onde, $q_{0}=$ risco socioambiental inicial $\mathrm{q}_{1}=\mathrm{q}_{0}+\Delta \mathrm{q}=$ risco socioambiental após a utilização deagrotóxicos; $\Delta q$ representaria o risco socioambiental adicional da utilização de agrotóxicos; ex, y, z ... seriam variáveis que influencia- riam a função DAA, a serem definidas durante a construção do modelo ${ }^{30}$.

Além disso, há uma variável temporal, que não pode ser desconsiderada no processo decisório dos produtores rurais, uma vez que os benefícios socioeconômi cos auferidos pelas comunidades rurais mais pobres seriam, em sua maioria, benefícios de curto prazo, que poderiam estar relacionados com a própria sobrevivência da comunidade. Enquanto que os prejuízos à saúde ambiental da mesma comunidade rural, advindos da utilização de agrotóxicos, poderiam ser de prazos mais longos e, portanto, desvalorizados em relação à necessidade de curto prazo (sobreviver).

\section{Discussão}

A teoria da maximização da eficiência econômica induziria uma busca de alocação dos recursos de forma mais eficiente. Com isso, levantou-se a hipótese da existência de uma relação inversa entre eficiência econômica e justiça socioambiental, uma vez que essa busca pela eficiência econômica poderia agravar situações de injustiça socioambiental, porque existi riam forças econômicas e políticas desiguais interagindo.

A utilização de agrotóxicos pareceu, na maioria dos casos, tentar maximizar a eficiência econômica e aumentar a produtividade rural, trazendo benefícios socioeconômicos adicionais. Porém, assumindo como verdadeira a relação inversa entre eficiência econômica ejustiça socioambiental, seria necessário que al gumas comunidades aceitassem (disposição a aceitar) certa quantidade de risco socioambiental adicional ocasionado pela utilização de agrotóxicos.

Uma das primeiras e mais importantes teorias sobre o comportamento humano diante das necessidades foi proposta por Abraham H. M aslow $^{31}$. Por esta teoria, as necessidades humanas estariam organizadas em uma pirâmide hierárquica com cinco níveis de necessidades, sendo o nível base da pirâmide as necessidades fisiológicas (sobrevivência).

Maslow defendeu que, enquanto os indivíduos não tivessem suas necessidades mais básicas (fisiológicas) atendidas, eles não se preocupariam em atender outras necessidades hierarquicamente superiores, ou seja, enquanto o problema de sobrevivência não estiver resolvido, os indivíduos não considerariam nas suas decisões necessidades de níveis mais elevados (e.g. segurança no trabalho). 
Esse raciocínio serviria como uma tentativa para explicar porque o produtor rural, na sua decisão de usar ou não agrotóxico, muitas vezes, por questão de sobrevivência, relevaria a um segundo plano, neste curto prazo, os seus efeitos negativos sobre a sua saúde e sobre o meio ambiente.

O sistema produtivo rural, apesar de competitivo, não se trata de um mercado econômico perfeito; uma imperfeição neste sistema éa grande diferença no poder e na qualidade e quantidade da informação entre os diversos atores sociais, sobre os possíveis riscos e benefícios socioambientais da utilização de agrotóxicos. Essa diferença tenderia a provocar ou agravar casos de injustiça socioambiental, uma vez que a disposição a aceitar (DAA) de cada produtor rural estaria diretamente relacionada à percepção de risco individual e esta estaria relacionada ao nível de informação.

Contudo, o risco socioambiental adicional que cada comunidade rural estaria disposta a aceitar (DAA) em troca de certas vantagens socioeconômicas deveria ser equilibrado de modo a garantir um nível socioambiental mais eficiente de prevenção e controle dos danos ambientais e prejuízos à saúde humana, tornando o sistema produtivo rural mais justo.

No entanto, o agrotóxico não pode ser sempre considerado um "bem" pois, normalmente, a sociedade tem rejeição aos seus riscos potenciais ao meio ambiente e à saúde humana; por isso, poderia ser chamado de "mal". A denominação "mal" indicaria que quantidades adicionais deste "bem" reduziriam a satisfação total da sociedade ${ }^{32}$.

Assim, para haver eficiência socioeconômica na utilização de agrotóxicos, num sentido mais amplo, seria necessário que os benefícios marginais advindos dos ganhos de produtividade rural superassem essas quantidades adicionais de "males" representados por eventuais riscos socioambientais adicionais que certas comunidades rurais teriam que incorrer. Assim, ainda existiriam algumas desigualdades socioambientais (injustiça socioambiental) que seriam imprescindíveis para manter a sociedade funcionando com os atuais padrões de produção, consumo e crescimento. Por isso, poderia-se afirmar que seria impossível eliminar todos os casos de injustiça socioambiental.

Portanto, a existência de uma relação inversa entre eficiência econômica e justiça socioambiental pode ser considerada, uma vez que a busca da maximização da eficiência econômica se da- ria através de um deslocamento de impactos negativos ao ambiente e à saúde humana, para comunidades de menor nível socioeconômico. Contudo, haveria a necessidade de legislação que regulasse a intensidade dessa relação, de forma que a sociedade, como um todo, passasse a operar em um nível socioambiental mais eficiente.

\section{Conclusões}

Este estudo analisou a relação inversa entre justiça socioambiental e eficiência econômica na utilização de agrotóxicos. A teoria da maximização da eficiência econômica induziria a uma busca de alocação dos recursos de forma mais eficiente, tais como reduzir o custo econômico através de ganhos de produtividade e deslocamento de riscos para comunidades de menor nível socioeconômico.

Porém, por essa lógica competitiva capitalista, a existência de forças socioeconômicas e políticas desiguais poderia provocar ou agravar situações de injustiça socioambiental. Com isso, pôde-se inferir a existência da relação inversa entre eficiência econômica e justiça socioambiental.

A utilização de agrotóxicos tenderia a elevar a eficiência econômica em locais com perda de produtividade. No entanto, poderia, também, representar agravamentos da injustiça socioambiental, uma vez que a população desses locais tenderia a aceitar uma certa quantidade de risco adicional provocada pela utilização de agrotóxicos.

Por isso, para que o sistema produtivo rural se torne mais eficiente economicamente e competitivo, existiria a necessidade de algumas comunidades estarem dispostas a aceitar (DAA) certa quantidade de risco socioambiental adicional. Portanto, os benefícios socioeconômicos da utilização de agrotóxicos em pequenas comunidades rurais deveriam ser balanceados com os conseqüentes riscos para o meio ambiente e para a saúde humana.

A relação inversa entre eficiência econômica e justiça socioambiental, na forma como foi discutida neste estudo, mostrou que uma possível solução para este problema seria regular (equilibrar) a quantidade de risco ao meio ambienteeà saúde humana adicional que uma comunidade poderia aceitar em troca de certas vantagens socioeconômicas adicionais.

Essas vantagens adicionais poderiam ser advindas dos ganhos de produtividade rural pela utilização de agrotóxicos, de forma que o sistema produtivo rural, como um todo, venha a ope- 
rar num nível socioambiental mais eficiente. Essa disposição a aceitar (DAA) estaria diretamente relacionada com o nível de percepção de risco dos atores sociais envolvidos, que por sua vez estaria atrelado ao nível de educação e à qualidade e quantidade de informação disponibilizada.

Este estudo, também, concluiu que deve ser feita uma análise custo-ben efício para verificar a viabilidade do Estado utilizar legislações para que se atinja esse nível de equilíbrio na utilização e controle dos agrotóxicos. Uma legislação para controlar agrotóxicos de forma mais restritiva poderia significar perdas socioeconômicas importantes, principalmente em comunidades de menor poder socioeconômico. Por outro lado, uma legislação mais permissiva poderia representar um risco maior ao meio ambiente eà saúde humana do que o ganho socioeconômico adicional correspondente.

Portanto, do ponto de vista da relação inversa entre eficiência econômica e justiça socioambiental, os benefícios socioeconômicos da utilização de agrotóxicos, especialmente por pequenas comunidades rurais, deveriam ser controlados e balanceados com os conseqüentes riscos para o meio ambiente e para a saúde humana em cada localidade.

Porém, ainda existiria certa quantidade de risco ao meio ambiente e à saúde humana que poderia ser considerada como necessária para sustentar certos processos produtivos sem os quais a sociedade comportaria prejuízos ainda maiores. Com isso, parece impossível a tarefa de eliminar na totalidade as situações de injustiça socioambiental na utilização de agrotóxicos.

Portanto, deve-se reconhecer que algumas diferenças na distribuição do risco socioambiental seriam necessárias para manter a sociedade nos moldes atuais. Isto significa afirmar quecerta quantidade de injustiça socioambiental pode ser esperada em prol da eficiência econômica, inferindo a existência da relação inversa entre eficiência econômica e justiça socioambiental.

Tentativas de equilibrar os efeitos positivos e negativos dessa relação inversa entre eficiência econômica e justiça ambiental passariam por legislações ambientais que pudessem exercer um controlemais rigoroso durantetodo ciclo devida da produção e da utilização de agrotóxicos e de todos seus resíduos, comprometendo todos os atores sociais, desde a indústria química e suas revendas até os produtores e trabalhadores rurais com uma gestão integrada e ambientalmente mais segura e saudável.

Logo, se reconhece a duplicidade de efeitos da utilização de agrotóxicos que resultou na relação inversa entre eficiência econômica e injustiça socioambiental. Por isso, o que se deveria buscar seriam sistemas de controle social, econômico, jurídico eambiental mais participativos ejustos, visando regular a utilização deagrotóxicos deforma controlar os efeitos negativos dessa relação inversa entre eficiência econômica e justiça socioambiental. 


\section{Referências}

1. Oliveira-Silva JJ, M eyer A. 0 sistema denotificação das intoxicações: o fluxograma da joeira. In: Peres F, M oreira JC, organizadores. É veneno ou é remédio? Agrotóxicos, saúdeeambiente. Rio de Janeiro: Fiocruz; 2003.

2. Lopes CA, Santos JRM. D oenças do tomateiro. Brasília: Embrapa; 1994.

3. Embrapa. Tomate para processamento industrial. Brasília: Embrapa; 2000.

4. op. cit., 2.

5. op. cit., 3.

6. Garcia EG. Segurança esaúdeno trabalho rural: a questão dos agrotóxicos. São Paulo: Fundacentro- M inisté rio do Trabalho e Emprego; 2001.

7. OPAS/OMS. M anual devigilância da saúde depopulações expostas a agrotóxicos. Brasília: OPAS/OM S, 1996.

8. op. cit., 2.

9. op. cit., 3

10. Coutinho JAG, et al. Uso de agrotóxicos no município de Pati do Alferes: um estudo de caso. Caderno de Geociências (IBGE) 1994; 10:23-31.

11. Castro JSM , Confalonieri U. Uso de agrotóxicos no município de Cachoeiras de M acacu (RJ). Rev C S Col 2005; 10(2):473-482.

12. Waswa F, GacheneCKK, Eggers H. Assessment of erosion damage in N domeand Ghazi, Taita Taveta, Kenya. GeoJ ournal 2002; 56(3):201-212.

13. Adeola FO. Cross-National Environmental Injustice and Human Rights Issues. Am Behav Sci 2000; 43(4): 686-706.

14. Boerner C, Lambert T. Environmental Injustice. Public Interest 1995. 118:61.

15. Lazarus RJ. Fairness in Environmental Law. Environmental Law 1997; 27(3):707-739.

16. op. cit., 14.

17. op. cit., 15.

18. M etcalfe M, M cWilliams B, Hueth B, Van Steenwyk R, David S, Zilberman D. The Economic Importance of Organophosphates in California Agriculture[relatório]. Berkeley: University of California; 2002.

19. Knutson RD, Smith, EG. Economic Impacts of the Elimination of Organophosphates and Carbamates on Texas Agriculture. AFPC Policy Working Paper 99-3. College Station: Texas A\&M University; 1999.
20. Agne S. Economic Analysis of Crop Protection Policy in Costa Rica. Publication Seriesn. 4. Germany: Universität Hannover; 1999.

21. Delgado IF, Paumgartten FJR. Intoxicações e uso de pesticidas por agricultores do Município de Paty do Alferes, RJ. Cad Saúde Pública 2004; 20(1):180-186.

22. Moreira JC, Jacob SC, Peres F, LimaJS, M eyer A, Silva, Jefferson JO, et al. Avaliação integrada do impacto do uso de agrotóxicos sobre a saúde humana em uma comunidade agrícola de Nova Friburgo, RJ. Rev C S Col 2002; 7(2):299-311.

23. Paumgartten FJR, Delgado IF, Oliveira ES, Alleluia IB, Barretto H HC, Kussumi TA. Levels of organochlorine pesticides in blood serum of agricultural workersfrom Rio de Janeiro State, Brazil. Cad Saúde Pública 1998; 14(supl 3):33-39.

24. Peres F, M oreira JC, Dubois GS. Agrotóxicos, saúde e ambiente: uma introdução ao tema, Parte I. In: Peres F, M oreira JC, organizadores. É veneno ou é remédio? Agrotóxicos, saúde eambiente. Rio de Janeiro: Fiocruz; 2003.

25. Sobreira, Antonio E. G. eAdissi, Paulo J. Agrotóxicos: falsas premissas e debates. Rev C S Coletiva 2003; 8(4): 985-990.

26. Hubert P, Barny M H, M oatti JP. Elicitation of Decision-M akers' Preferences to Major Hazards. Risk Anal 1991; 11(2).

27. Steg L, Stevers I. Cultural Theory and Individual Perceptions on Environmental Risks. Environ Behav 2000; 32(2):250-269.

28. M cdaniels TL, Kamlet M S, Fischer GW. Risk Perception and the Value of Safety. Risk Anal 1992; 12(4).

29. op. cit., 11.

30. Kolstad, CD. Environmental Economics. Oxford: Oxford University Press; 2000.

31. Maslow AH. Theory of Human M otivation. Psychological Review 1943; (50):370-396.

32. Varian HR. M icroeconomia - princípios básicos. 2a Ed. Rio de Janeiro: Campus; 1994.

Artigo apresentado em 18/10/2005

A provado em 18/04/2006

Versão final apresentada em 27/07/2006 